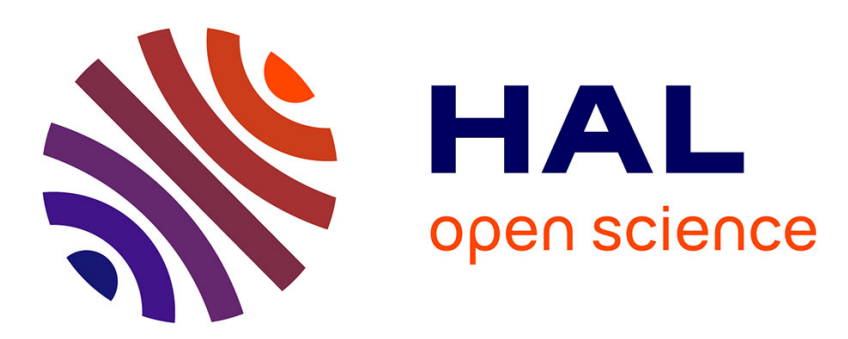

\title{
A distributed modelling approach to assess the use of Blue and Green Infrastructures to fulfil stormwater management requirements
}

Pierre-Antoine Versini, N. Kotelnikova, A. Poulhes, I. Tchiguirinskaia, D. Schertzer, F. Leurent

\section{To cite this version:}

Pierre-Antoine Versini, N. Kotelnikova, A. Poulhes, I. Tchiguirinskaia, D. Schertzer, et al.. A distributed modelling approach to assess the use of Blue and Green Infrastructures to fulfil stormwater management requirements. Landscape and Urban Planning, 2018, 173, pp.60-63. 10.1016/j.landurbplan.2018.02.001 . hal-02060156

\section{HAL Id: hal-02060156 \\ https://hal-enpc.archives-ouvertes.fr/hal-02060156}

Submitted on 15 Mar 2019

HAL is a multi-disciplinary open access archive for the deposit and dissemination of scientific research documents, whether they are published or not. The documents may come from teaching and research institutions in France or abroad, or from public or private research centers.
L'archive ouverte pluridisciplinaire HAL, est destinée au dépôt et à la diffusion de documents scientifiques de niveau recherche, publiés ou non, émanant des établissements d'enseignement et de recherche français ou étrangers, des laboratoires publics ou privés. 
and Urban Planning

Elsevier Editorial System(tm) for Landscape

Manuscript Draft

Manuscript Number: LAND-D-18-00056R1

Title: A distributed modelling approach to assess the use of Blue and Green Infrastructures to fulfil stormwater management requirements

Article Type: Research Note

Keywords: blue green infrastructures, stormwater management, distributed modelling

Corresponding Author: Dr. Pierre-Antoine Versini, Dr

Corresponding Author's Institution: Ecole des Ponts ParisTech

First Author: Pierre-Antoine Versini, Dr

Order of Authors: Pierre-Antoine Versini, Dr; Natalia Kotelnikova, Dr.; Alexis Poulhes, Dr.; Ioulia Tchiguirinskaia, Dr.; Daniel Schertzer, Prof.; Fabien Leurent, Prof.

Abstract: Blue and green infrastructures (B\&GI) are nature-based solutions considered as particularly efficient to reduce the potential impact of new and existing developments with respect to stormwater issues. In order to assess their performances at some large scales compatible with urban projects, adapted distributed rainfall-runoff models are required. The latest advancements of the Multi-Hydro platform have made possible the representation of such B\&GI. Applied in a virtual new urban development project located in the Paris region, Multi-Hydro has been used to simulate the impact of B\&GI implementation, and their ability to fulfil regulation rules authorizing the connexion to the sewer network. The results show that a combination of several B\&GI, if they are widely implemented, could represent an efficient tool to meet regulations at the parcel scale, as they can reduce runoff volume about 90\%. 
A distributed modelling approach to assess the use of Blue and Green Infrastructures to fulfil stormwater management requirements

P.-A. Versini ${ }^{1, *}$, N. Kotelnikova ${ }^{2}$, A. Poulhes ${ }^{2}$, I. Tchiguirinskaia ${ }^{1}$, D. Schertzer ${ }^{1}$, F. Leurent ${ }^{2}$

${ }^{1}$ HMCo, Ecole des Ponts ParisTech, Champs-sur-Marne, France ${ }^{2}$ LVMT, Ecole des Ponts ParisTech, Champs-sur-Marne, France

${ }^{*}$ Corresponding author: pierre-antoine.versini@enpc.fr 

8

\section{A distributed modelling approach to assess the use of Blue and Green}

\section{Infrastructures to fulfil stormwater management requirements}

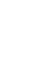

Blue and green infrastructures (B\&GI) are nature-based solutions considered as particularly efficient to reduce the potential impact of new and existing developments with respect to stormwater issues. In order to assess their performance at some large scales compatible with urban projects, adapted distributed rainfall-runoff models are required. The latest advancements of the Multi-Hydro platform have made possible the representation of such B\&GI. Applied in a virtual new urban development project located in the Paris region, Multi-Hydro has been used to simulate the impact of B\&GI implementation, and their ability to fulfil regulation rules authorizing the connexion to the sewer network. The results show that a combination of several B\&GI, if they are widely implemented, could represent an efficient tool to meet regulations at the parcel scale, as they can reduce runoff volume about $90 \%$.

Key words: blue green infrastructures, stormwater management, distributed modelling

(1)

\section{Introduction}

Blue and Green Infrastructures (B\&GI), including green roof, bio-retention swale, porous pavement, harvesting tank, soakaway or pond for instance, can provide multiple benefits to urban areas affected by both climate change and urbanization effects: urban heat island reduction, biodiversity conservation, reduced buildings energy requirements,... Last but not least, they appear to be particularly efficient in stormwater management (Liao et al, 2017). By detention, infiltration and evapotranspiration processes, they can be used to control urban runoff at the local scale.

The hydrological performance and benefit of B\&GI have been shown in numerous studies conducted at small scales: Kamali et al. (2017) for porous pavement, 3 Chapman and Horner (2010) for bioretention system, or Stovin et al. (2012) for green 4 roofs. Nevertheless, their performance and interaction at higher scales (urban project) 
are still uncertain and insufficiently quantified. Modelling tools are required to consider B\&GI configuration and optimize their performance, as most of the existing models are focused on one or very few assets such as green roofs (Versini et al., 2015). Few of them are technically able to combine dynamically several infrastructures, but usually in a semi-distributed approach that mixes several types of landcover (road, house, grass, park...), and implies some huge difficulties to adjust $a$ priori the parameters without observed data. It is the case of the Storm Water Management Model, as shown in Lucas et al. (2015) or Palla and Gnecco (2015) among others. To properly assess B\&GI performance on a large set of spatial scales, a hydrologic model characterized by a high spatial resolution is also required. Such a structure is necessary to consider heterogeneous surfaces, and the associated dynamics due to the layout of impervious and pervious areas.

Based on these considerations, the main objective of this research note is to assess the performance of B\&GI in stormwater management at the urban project scale. A distributed modelling approach has been chosen to especially study the respective performance of a B\&GI set, and their evolution regarding storm event return periods.

\section{Presentation of the case study: the "Echangeur" project}

The virtual urban project called "Echangeur" has been designed by a group of students during a specialized master training devoted to the "Ecodesign of Sustainable Cities". Supported by the Academic Chair on the Eco-design of building sets and infrastructure established by ParisTech and the Vinci group (see Kotelnikova et al., 2016 for a detailed presentation), the main activity of this course is to design a sustainable neighborhood materialized by a layout plan. Located in the eastern

61 suburbs of Greater Paris (Champs-sur-Marne, France) and covering an area of 10.66

62 ha, the plan proposed by the students for the Echangeur project (Figure 1) hosts accommodation for 5900 inhabitants and activities with the creation of 1150 jobs.

64 This plan must also fulfill stormwater management requirements concerning the connection to the stormwater network. Here the discharge at the parcel outlet has to be lower than a reference threshold of $10 \mathrm{l} / \mathrm{s} / \mathrm{ha}$ for a rainy event characterized by a 20 -years return period. In the Paris region, this corresponds to a 30-minute rainfall event characterized by a $50 \mathrm{~mm} / \mathrm{h}$ intensity. 
70 Figure 1. Layout of the Echangeur catchment differentiating the different land use

71 classes

73 Due to a lack of space, the construction of a large storage unit has not been 74 considered. Several blue and green infrastructures have been planned to fulfil this stormwater regulation rule: (i) Green spaces (grass, forest and vegetable gardens), (ii) green roofs, (iii) green swales (swaled drainage course with sloped sides and filled with vegetation and riprap), (iv) small retention basins, (v) porous pavement.

\section{Materials and method}

\section{3-1 The Multi-Hydro model}

82

The Multi-Hydro distributed rainfall-runoff model represents a well-adapted tool to assess hydrological impacts at the urban scale (Giangola-Murzyn, 2014, Ichiba et al, 2017). For each time step, Multi-Hydro provides overland water depth (flooding) and infiltration maps, but also discharge values for each pipe and junction of the stormwater network. Multi-Hydro is currently being developed at the XXX to take into account the wide complexity of urban environments. The latest advancements have made possible the representation of several "resilience infrastructures" such as basins, barriers, and green roof (see Versini et al., 2016 for details). Based on these previous works, Multi-Hydro has been adapted to reproduce the hydrological behaviour of the mentioned B\&GI planned in the Echangeur project.

Multi-Hydro has been implemented on this case study to simulate its hydrological response with a resolution of $5 \mathrm{~m}$ in space and 5 minutes in time. Based on the layout plan, the input data required by the model (map of topography, landuse and stormwater network) were produced by using adapted GIS tools.

\section{3-2 Land use scenarios}

101 In order to study the relative contribution of each implemented B\&GI, different land 102 use scenarios have been established: (0) there is no blue or green infrastructure, but 
103 only impervious surfaces such as roads, buildings and pavements, (1) Green spaces 104 are implemented, (2) Every building roof is covered with an extensive green roof, (3)

105 Green swales are implemented, (4) Impervious pavements are replaced with porous 106 ones on the pedestrian area, (5) Most of the stormwater network outfalls are 107 connected to two small retention basins, (6) All of the B\&GI mentioned above are 108 implemented.

\section{3-3 Rainfall scenarios}

112 To quantify the relative performance of B\&GI regarding stormwater management

113 issue, several rainfall scenarios have been provided. These are synthetic hyetographs 114 characterized by a homogenous precipitation and based on the specific Intensity115 Duration-Frequency relationship (established in a station located $20 \mathrm{~km}$ away from 116 the studied area by Météo-France). They were computed for a 30-minute duration 117 (close to the watershed concentration time) and several return periods (see Table 1).

119 Table 1. Rainfall intensity (expressed in $\mathrm{mm} / \mathrm{h}$ ) for the 8 considered return periods

121 3-4 Work plan

123 Multi-Hydro was applied on every land use and rainfall scenario ( $7 \times 8$ simulations).

124 Some of the resulting hydrographs are illustrated in Figure 2 and analysed in the 125 following. Note that two indicators were used to assess B\&GI performance: runoff 126 volume $(\Delta V)$ and peak discharge $(\Delta Q p)$ reductions:

130 Where $Q p_{0}$ and $V_{0}$ refer to peak discharge and runoff volume computed for the 131 impervious situation, whereas $Q p_{i}$ and $V_{i}$ correspond to those computed for the 132 different B\&GI scenarios.

\section{Presentation of the results}

135 For the impervious situation, most of the rainfall volume is transferred to the basin 136 outfalls. Only initial losses and water stored in local depression can be deduced. 
137 Regarding 30-minute duration events, peak discharge reaches $200 \mathrm{l} / \mathrm{s}$ to $1200 \mathrm{l} / \mathrm{s}$. It is 138 worth noting that regulation threshold is exceeded whatever the return period of the 139 considered storm event.

141 When $11.6 \%$ of the total area is covered by green spaces (Scenario 1), runoff volume 142 and peak discharge decrease by approximately $10-15 \%$ for the more frequent events, 143 and less than $10 \%$ for the strongest ones. In these cases, infiltration capacity of green 144 spaces is reduced, and some water is finally drained to the stormwater network

146 The green roof implantation proposed in Scenario 2 -representing $42.3 \%$ of the 147 watershed area- induces both runoff volume and peak discharge reduction starting 148 from $15 \%$ to $25 \%$ for the more frequent storm events, and dropping to about $5 \%$ for 149 the heaviest ones. Green roofs appear to be particularly efficient at the beginning of 150 the storm, when they can temporarily store water in the substrate.

In Scenario 3, Green swales represent a small part of the studied basin (5.5\%), but they drain water from surrounding elements (almost $30 \%$ of the total area). It is

154 illustrated by some runoff volume and peak discharge reductions that vary from $30 \%$ 155 for the 1 -month event to $17 \%$ for the 20 -year one.

157 As porous pavements represent $31.5 \%$ of the whole area, their implementation in 158 Scenario 4, characterized by a high storage capacity, significantly influences the 159 hydrological response of the catchment. Both runoff volume and peak discharge 160 decrease about $30-40 \%$ depending on the considered rainfall event.

162 Retention basins drawn up in Scenario 5 represent the most effective infrastructure in 163 terms of runoff reduction as they drain two thirds of the catchment area. Both runoff 164 volume and peak discharge decrease of about $70 \%$ for the more common storm 165 events. For the highest events, the total storage capacity $\left(1300 \mathrm{~m}^{3}\right)$ is reached. From 166 that time, the exceeded water is routed to the stormwater network and produces a 167 "step" in the catchment response.

169 The implementation of all of the B\&GIs on the Echnageur project (Scenario 6) is 170 obviously the most effective configuration. Both peak discharge and runoff volumes 
171 are reduced by about $90 \%$ on the wide range of return periods, and the regulation rule

172 of $10 \mathrm{l} / \mathrm{s} / \mathrm{ha}$ is almost always met (except for the two main events).

173

174 Figure 2. Presentation of the simulated hydrographs for different rainfall events and

175 B\&GI scenarios. Orange horizontal solid line corresponds to the $10 \mathrm{l} / \mathrm{s} / \mathrm{ha}$ regulation.

176

1775 Conclusions and perspectives

178

179 A combination of B\&GI appears to be the best solution to significantly reduce the 180 quantity of water flowing into the sewage network during storm events, and to fulfil 181 regulation rules established by local stormwater managers. The distributed structure 182 of Multi-Hydro and the possibility to reproduce a large set of B\&GI allow the 183 realization of such detailed and dynamic impact studies. As Multi-Hydro is still in 184 development, additional B\&GI could be added in the future, and among these, 185 different configurations could be tested (ie. several green roofs differentiated by their substrate porosity or thickness).

The presented results must be taken with caution, as they depend on the catchment configuration, especially on the combination of impervious and pervious surfaces, but also on its geometry and on the sewage network arrangement. Moreover, it should also be noticed that initial conditions have not been considered in this study. Every B\&GI was assumed to be empty / unsaturated at the beginning of every rainfall event.

193 Future versions of Multi-Hydro should take into account evapotranspiration processes and detention basins draining during dry periods to better estimate the initial state of the system. The succession of several rainfall events should also be possible to study

196 B\&GI performance in more realistic conditions, as it is usually the case for rainwater 197 harvesting tank or detention basin sizing.

\section{Acknowledgments}

\section{References}

202 Chapman, C., \& Horner, R.R. (2010). Performance assessment of a street- drainage bioretention system. Water Environ. Res., 82 (2), 109-119 
Giangola-Murzyn, A. (2014). Modélisation et paramétrisation hydrologique de la ville, résilience aux inondations, $\mathrm{PhD}$ thesis, Université Paris-Est, $260 \mathrm{pp}$.

Ichiba, A., Gires, A., Tchiguirinskaia, I., Schertzer, D., Bompard, P., \& Ten Veldhuis, M.-C. (2017). Scale effect challenges in urban hydrology highlighted with a distributed hydrological model. Hydrol. Earth Syst. Sci. Discuss., https://doi.org/10.5194/hess-2017-286

Kotelnikova, N., De Bartoli, A., Féraille,A., \& Leurent, F. (2016). Integrating Urban

Kamali, M., Delkash, M., \& Tajrishy, M. (2017). Evaluation of permeable pavement responses to urban surface runoff, Journal of Environmental Management, 187, 43-53 Ecodesign in French engineering curricula: an example at École des Ponts ParisTech. International Conference on Sustainable Built Environment, Hamburg, Germany

Liao, KH., Deng, S., Tan, P.Y. (2017). Blue-Green Infrastructure: New Frontier for Sustainable Urban Stormwater Management. In: Tan P., Jim C. (eds) Greening Cities. Advances in 21st Century Human Settlements. Springer, Singapore

Lucas, W.C., \& Sample, D.J. (2015). Reducing combined sewer overflows by using outlet controls for Green Stormwater Infrastructure: case study in Richmond, Virginia. Journal of Hydrology, 520, 473-488

Palla, A., \& Gnecco, I. (2015). Hydrologic modeling of Low Impact Development systems at the urban catchment scale, Journal of Hydrology, 528, 361-368

Stovin, V., Vesuviano, G. \& Kasmin, H. (2012). The hydrological performance of a green roof test bed under UK climatic conditions. Journal of Hydrology, 414$415,148-161$.

Versini, P.A., Gires, A., Tchiguirinskaia, I., \& Schertzer, D. (2016). Toward an operational tool to simulate green roof hydrological impact at the basin scale: a new version of the distributed rainfall-runoff model Multi-Hydro. Water Science and Technology, 74(8), 1845-1854.

Versini, P.A., Jouve, P., Ramier, D., Berthier, E. \& de Gouvello, B. (2015). Use of green roofs to solve storm water issues at the basin scale - Study in the Hautsde-Seine county (France). Urban Water Journal. http://dx.doi.org/10.1080/1573062X.2014.993993 


\section{List of Tables}

237

238 Table 1. Rainfall intensity (expressed in $\mathrm{mm} / \mathrm{h}$ ) for the 8 considered return periods 239

240

241

242

243 
245

\begin{tabular}{|l|l|l|l|l|l|l|l|l|}
\hline & 1 month & 3 months & 6 months & 1 year & 2 years & 5 years & 10 years & 20 years \\
\hline $\mathrm{D}=30 \mathrm{~min}$ & 8.0 & 14.4 & 19.7 & 25.9 & 31.4 & 42.0 & 50.1 & 58.2 \\
\hline
\end{tabular}

246

247 


\section{Figure 1}

Click here to download high resolution image

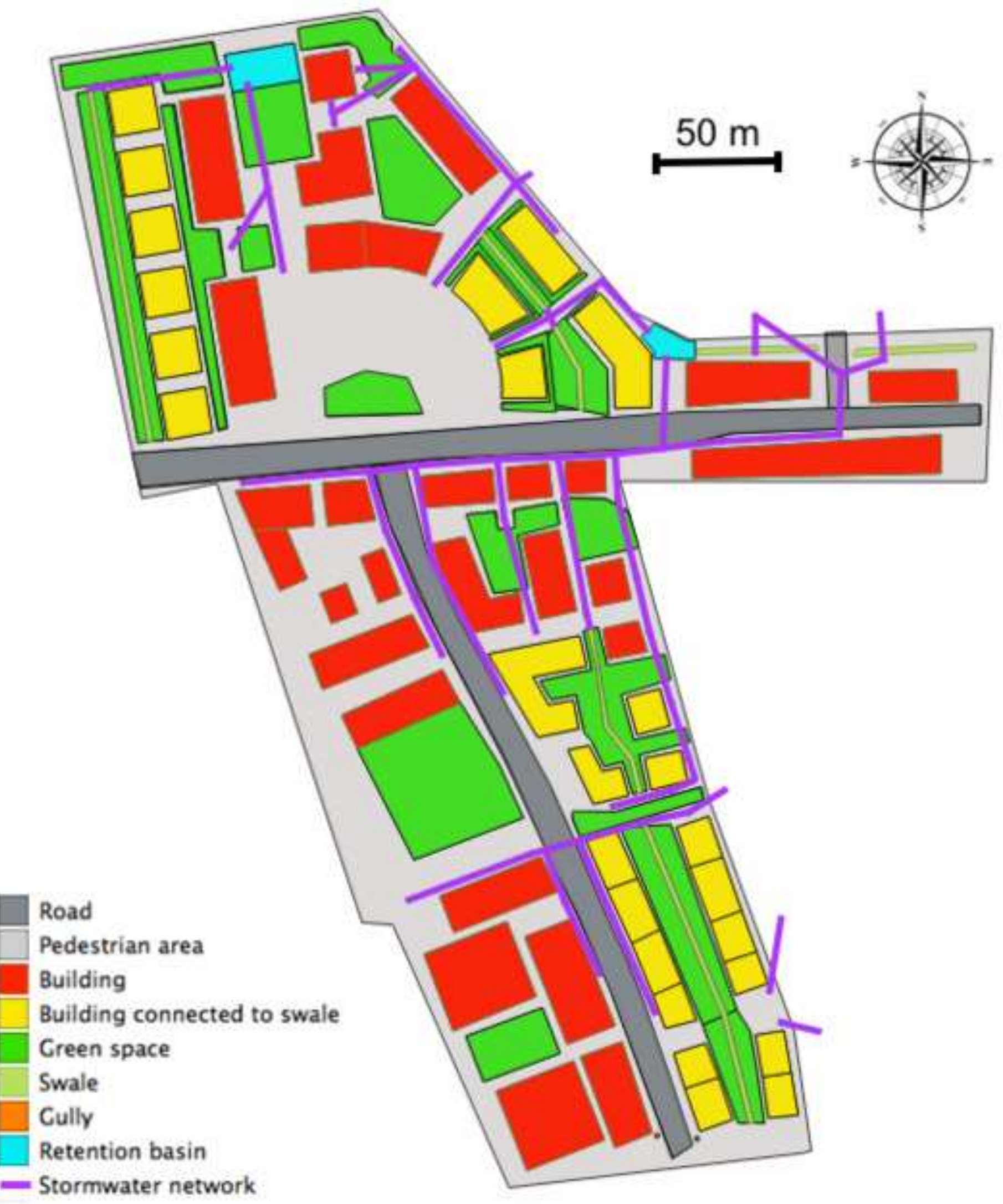


Click here to download high resolution image
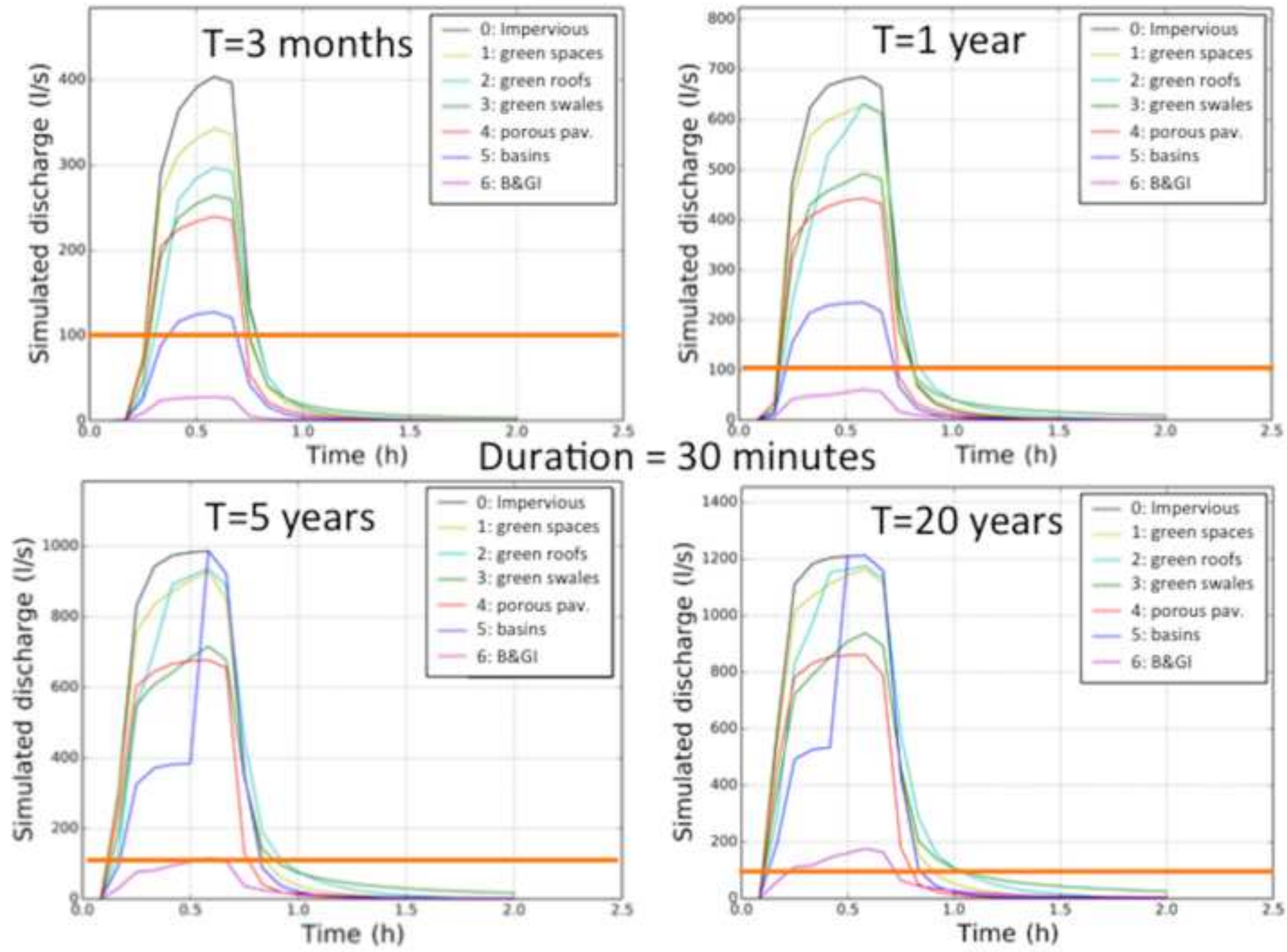